\title{
Mathematical Model-Based Accelerated Development of Extended-release Metformin Hydrochloride Tablet Formulation
}

\author{
W. Chen, ${ }^{1}$ D. Desai, ${ }^{1,6}$ D. Good, ${ }^{1}$ J. Crison, ${ }^{1}$ P. Timmins, ${ }^{2}$ S. Paruchuri, ${ }^{3}$ J. Wang, ${ }^{4}$ and K. Ha ${ }^{5}$
}

Received 21 July 2015; accepted 24 September 2015; published online 19 October 2015

\begin{abstract}
A computational fluid dynamic (CFD) model was developed to predict metformin release from a hydroxypropylmethylcellulose (HPMC) matrix-based extended-release formulation that took into consideration the physical and chemical properties of the drug substance, composition, as well as size and shape of the tablet. New high dose strength $(1000 \mathrm{mg})$ tablet geometry was selected based on the surface area/volume (SA/V) approach advocated by Lapidus/Lordi/Reynold to obtain the desired equivalent metformin release kinetics. Maintaining a similar SA/V ratio across all extended-release metformin hydrochloride (Met XR) tablet strengths that had different geometries provided similar simulations of dissolution behavior. Experimental dissolution profiles of three lots of high-strength tablets agreed with the simulated release kinetics. Additionally, a pharmacokinetic absorption model was developed using GastroPlus ${ }^{\mathrm{TM}}$ software and known physicochemical, pharmacokinetic, and in vitro dissolution properties of metformin to predict the clinical exposure of the new high strength $(1000 \mathrm{mg})$ tablet prior to conducting a human clinical bioequivalence study. In vitro metformin release kinetics were utilized in the absorption model to predict exposures in humans for new 1000-mg Met XR tablets, and the absorption model correctly projected equivalent in vivo exposure across all dose strengths. A clinical bioequivalence study was pursued based on the combined modeling results and demonstrated equivalent exposure as predicted by the simulations.
\end{abstract}

KEY WORDS: diffusion; CFD; GastroPlus; HPMC; mathematical model; scale-up; surface area; volume.

\section{INTRODUCTION}

Hydroxypropylmethylcellulose (HPMC) is a commonly used drug release controlling polymer in a matrix tablet formulation. Its detailed characterization has been reported by Siepmann and Peppas (1). The same authors also summarized empirical and semi-empirical mathematical models reported in pharmaceutical literature to explain the drug release mechanism from HPMC-based systems (1). Additionally, a mathematical model showing the importance of tablet surface area/ volume ratio was reported by Lapidus and Lordi $(2,3)$. However, the detailed investigation of this concept and its practical utility were reported some time later by Reynolds et al. (4), who verified several key concepts. Tablets with same surface area, but different surface area/volume ratio did not result in

\footnotetext{
${ }^{1}$ Drug Product Science and Technology, Bristol-Myers Squibb Co., P.O. Box 191, New Brunswick, New Jersey 08903-0191, USA.

${ }^{2}$ Drug Product Science and Technology, Bristol-Myers Squibb, Moreton, Merseyside CH46 1QW, UK.

${ }^{3}$ Appco Pharmaceuticals, Somerset, New Jersey, USA.

${ }^{4}$ Teva Pharmaceuticals, North Wales, Pennsylvania, USA.

${ }^{5}$ Analytical and Bioanalytical Development, Bristol-Myers Squibb Co., P.O. Box 191, New Brunswick, New Jersey 08903-0191, USA.

${ }^{6}$ To whom correspondence should be addressed. (e-mail: divyakant.desai@bms.com)
}

similar drug release. Tablets with larger surface area/volume ratio had faster drug release profiles. One of the most useful findings was that drug release from HPMC matrix tablet was comparable for similar surface area/volume ratios within the same tablet shape as well as among different shapes (4). This finding could be immensely useful to pharmaceutical scientists needing to develop additional higher or lower strength tablets of an established or to change tablet shapes to distinguish various tablet strengths. Adapting a modified release tablet surface area/volume ratio to produce a drug release profile similar to that of the reference tablet can increase the likelihood of bioequivalence between the test and reference formulations.

The rapid development of a high-strength $(1000 \mathrm{mg})$ extended-release metformin hydrochloride (Met XR) tablet formulation was pursued through a mechanistic analysis that employed multiple fundamental modeling techniques to ensure robust performance. The high-strength tablet formulation was a common composition to existing commercial tablet strengths. Based on the scale-up and post-approval change (SUPAC) guidance for a modified release formulation, in absence of an in vitro in vivo correlation (IVIVC), a bioequivalence (BE) study would be needed if there is a change in manufacturing site, manufacturing process, or more than $10 \%$ change in the amount of release controlling excipient (5). Additionally, a higher tablet strength 
from the reference strength (case of this $1000 \mathrm{mg}$ Met XR) would also require a BE study (6). To minimize the BE risk, three mathematical modeling approaches were utilized. Firstly, Lapidus and Lordi's model was applied to maintain a similar surface area/ volume ratio during the scale-up of the new HPMC-based extended-release 1000-mg Met XR. Second, the dissolution behavior of the prototype tablet geometries were predicted using Gambit and Fluent modeling software before tablet manufacture or in vitro testing was pursued. Third, the physicochemical, pharmacokinetic, and in vitro release properties of high-strength metformin hydrochloride tablets were used to construct a GastroPlus pharmacokinetic absorption model to predict the clinical exposure of the new strength. This model-based development of a high-strength Met XR tablet formulation demonstrates a valuable approach for applying mechanistic models to obtain robust drug product clinical performance.

\section{MATERIALS}

Metformin hydrochloride was supplied by Merck Serono (Merck Serono, Calais, France). The following ingredients were used as received from the suppliers: sodium carboxymethylcellulose USP (FMC, Philadelphia, PA), hypromellose 2208 USP (Colorcon, West Point, PA), and magnesium stearate NF (Mallinckrodt, St. Louis, MO).

\section{METHODS}

Tablet Formulation. The tablet formulation design and the mechanism of metformin release have been previously published $(7,8)$. The tablet formulation can be described as a twophase system. The inner phase consists of fine metformin particles in intimate contact with sodium carboxymethylcellulose (SCMC). This drug-SCMC combination is then dispersed in a second continuous matrix of a second hydrophilic polymer, hypromellose. When a tablet formed from this blend $(69 \% \mathrm{w} /$ $w$ metformin hydrochloride) comes in contact with fluid, the polymer hydrates and causes a tablet to develop a gel-like mass. Metformin slowly diffuses through the gel-like mass (7).

Metformin hydrochloride and sodium carboxymethylcellulose were mixed in a PMA 300 high shear granulator. The mix was granulated using purified water. The wet granules were wet milled using a comil and then dried to less than $2 \% w / w$ residual moisture in GPCG 120 (Glatt Particle Coater Granulator 120). The granulation batch size was $64 \mathrm{~kg}$ and four batches of granulation were combined for drying in GPCG 120. The dried granules were milled using Fitzmil and mixed with hypromellose and magnesium stearate in a bin blender. The final blend was compressed into 1450-mg tablet weight using Korsch XL 400 (Korsch Maschinenfabrik, Berlin, Germany) fitted with a capsule-shaped D tooling. Within the capsule shapes, seven different dimensions (length, width, thickness, and band thickness) were evaluated (Table I).

Dissolution. The tablet dissolution was conducted in $1000 \mathrm{~mL}$ in $50 \mathrm{mM} \mathrm{pH} 6.8$ phosphate buffer, $50 \mathrm{mM} \mathrm{pH} 4.5$ acetate buffer, or $0.1 \mathrm{~N} \mathrm{HCl}$ at $37^{\circ} \mathrm{C}$ using the basket at $100 \mathrm{rpm}$. The tablet dissolution of Met XR 750 was conducted using the basket speed of $50 \mathrm{rpm}$. Dissolution of $2 \times 500 \mathrm{Met}$ $\mathrm{XR}$ was conducted using paddles at $100 \mathrm{rpm}$. Samples were taken at 60, 180, and $600 \mathrm{~min}$. The sample volume was $10 \mathrm{~mL}$.
For HPLC method for Met XR Dissolution, $50 \mathrm{mM}$ pH 6.8 phosphate buffer was used as a mobile phase at the flow rate of $1.5 \mathrm{ml} / \mathrm{min}$ through a $2-\mathrm{mL}$ sample loop with an in-line $2-\mu$ filter. The sample injection volume was $15 \mu$ l. Metformin was detected at the wavelength of $232 \mathrm{~nm}$. The run time was $4 \mathrm{~min}$.

Dissolution Simulation. A computational fluid dynamic (CFD)-based mathematical model was developed to predict metformin hydrochloride release from a matrix-based formulation that takes the physical and chemical properties of the drug substance, composition, and size and shape of the tablet into consideration, particularly to simulate the dissolution profile for an arbitrary shape and size of the tablet compared with the cylinder shape of the tablet normally used before, since CFD can mimic an arbitrary geometry of the tablet and has a well-established partial differential equation solver to obtain a converged solution easily. The geometry of the tablet was meshed using Gambit software (Fig. 1) and used in the dissolution simulations run on Fluent software.

GastroPlus Pharmacokinetic Absorption Model Development and Simulations. Using the physicochemical and pharmacokinetic properties of metformin hydrochloride, a pharmacokinetic absorption model was previously developed using GastroPlus ${ }^{\mathrm{TM}}$ V.7.0 software (9). The model was used to simulate the mean plasma concentrations for a wide range of drug release profiles and gastric emptying time for a 1000-mg dose of metformin. A wide range of drug release rates proportional to the square root of time that approximate the behavior of a swellable hydrophilic matrix were used to simulate the clinical exposure. These release profiles varied from 100 to $40 \%$ drug being released in $3 \mathrm{~h}$, which corresponds to the mean transit time for the small intestine where metformin exhibits the greatest permeability. Gastric emptying times used in the simulations ranged from $T_{50}=0.25 \mathrm{~h}$ up to $T_{50}=3.00 \mathrm{~h}$. The Cmax and AUC (0-24) were determined from the simulated plasma concentrations and then plotted as a function of the percent drug released at $3 \mathrm{~h}$ and the simulated gastric emptying time. The model assumes that the drug release profiles represent the in vivo drug release from the formulations. These plots created a surface from which one can determine the drug release profile having the least impact from gastric emptying due to food and size exclusion effects.

Bioequivalence Study. The first bioequivalence (BE) study was conducted comparing $2 \times 500$ Glucophage XR (reference product) to $1 \times 1000 \mathrm{mg}$ Met XR (test product) in a 13 healthy subjects in randomized two period two treatment crossover study. The numbers of subjects was increased to 30 in the second BE study which was similar to the first BE study. The blood samples were collected after dosing at 15,30 , and $45 \mathrm{~min}$ and at $1,1.5,2,3,4,5,6,7,8,9,10,12,18,24,36$, and $48 \mathrm{~h}$. Plasma samples were analyzed using the previously reported method (7).

\section{RESULTS AND DISCUSSION}

Several mathematical models have been proposed to characterize the drug release $(10,11)$. For the present study, a CFD-based model was developed to quantitatively describe 
Table I. Dimensions of Tablet Tooling Design Considered for Met XR 1000 mg Tablet

\begin{tabular}{|c|c|c|c|c|c|c|c|}
\hline & $\begin{array}{l}\text { Metformin XR } \\
750 \text { As a } \\
\text { reference }\end{array}$ & $\begin{array}{l}\text { Capsule shape } \\
\text { (Elizabeth } \\
\text { carbide) }\end{array}$ & $\begin{array}{l}\text { Modified } \\
\text { Capsule } \\
\text { (Natoli) }\end{array}$ & $\begin{array}{l}\text { Modified capsule } \\
\text { (Elizabeth } \\
\text { carbide) }\end{array}$ & $\begin{array}{l}\text { Oval } \\
\text { (Elizabeth } \\
\text { carbide) }\end{array}$ & $\begin{array}{l}\text { Oval/modified } \\
\text { capsule } \\
\text { (Elizabeth } \\
\text { carbide) }\end{array}$ & $\begin{array}{l}\text { Modified } \\
\text { capsule } \\
\text { (Elizabeth } \\
\text { carbide) }\end{array}$ \\
\hline Drawing ID & $\mathrm{R}$ & A & $\mathrm{B}$ & $\mathrm{C}$ & $\mathrm{D}$ & $\mathrm{E}$ & $\mathrm{F}$ \\
\hline Length (in.) & 0.748 & 0.887 & 0.925 & 0.848 & 0.910 & 0.887 & 0.960 \\
\hline Width (in.) & 0.3642 & 0.3450 & 0.3750 & 0.4750 & 0.4750 & 0.4100 & 0.3800 \\
\hline Thickness (in.) & 0.2480 & 0.3290 & 0.2888 & 0.24350 & 0.2560 & 0.3030 & 0.2903 \\
\hline Band thickness (in.) & 0.1300 & 0.2050 & 0.1706 & 0.1635 & 0.1560 & 0.1670 & 0.1563 \\
\hline SA $\left(\right.$ in $\left.^{2}\right)$ & 0.7736 & 1.0347 & 1.0611 & 1.0912 & 1.0810 & 1.0331 & 1.0645 \\
\hline Vol $\left(\mathrm{in}^{3}\right)$ & 0.0485 & 0.0754 & 0.0745 & 0.0745 & 0.0747 & 0.0754 & 0.0754 \\
\hline $\mathrm{SA} / \mathrm{Vol}(1 / \mathrm{in})$. & 15.94 & 13.73 & 14.24 & 14.64 & 14.48 & 13.70 & 14.12 \\
\hline Width-thickness (in.) & 0.1162 & 0.0160 & 0.0862 & 0.2315 & 0.2190 & 0.1070 & 0.0897 \\
\hline Comments & Reference & $\begin{array}{l}\text { Twining issue } \\
\text { during } \\
\text { coating }\end{array}$ & $\begin{array}{l}\text { Too long to } \\
\text { swallow } \\
\text { easily }\end{array}$ & $\begin{array}{l}\text { Orientation issue } \\
\text { during tablet } \\
\text { printing }\end{array}$ & $\begin{array}{l}\text { Too long to } \\
\text { swallow } \\
\text { easily }\end{array}$ & Preferred & $\begin{array}{l}\text { Too long to } \\
\text { swallow } \\
\text { easily }\end{array}$ \\
\hline
\end{tabular}

The parameters for selected tooling design is highlighted to facilitate comparison with the similar parameters for other tooling designs in inches, $S A$ surface area

the drug transport in the matrix of the tablet and the drug release process. The following assumptions were made:

1. The drug is initially uniformly distributed in the tablet.

2. Only the drug diffuses in the tablet with a constant diffusivity, and the diffusion is isotropic.

3. Perfect sink condition is maintained at the surface of the tablet.

4. The oval tablet is used in the simulation shown in Fig. 1

Based on Fick's second law of diffusion, the drug mass transfer can be described by Eq. 1 (shown below) in the cylindrical coordinates. Here, $c_{\mathrm{d}}$ and $D_{\mathrm{d}}$ are the concentration and diffusion coefficient of the drug. This partial differential equation can be solved numerically using the CFD package FLUENT 14.5 and taking into account the given initial and boundary conditions as well as the drug diffusivity. The mesh (the computation domain) of Met XR1000 tablet for the CFD analysis was created by the preprocessor GAMBIT software (part of FLUENT package, Ansys Fluent 14.5 Document, 2013, ANSYS, Inc, Canonsburg, PA 15317) shown in Fig. 1. The detailed simulation settings and procedures were also published earlier (12).

$\frac{\partial c_{\mathrm{d}}}{\partial t}=\left\{\frac{\partial}{\partial r}\left(D_{\mathrm{d}} \frac{\partial c_{\mathrm{d}}}{\partial r}\right)+\left(\frac{D_{\mathrm{d}}}{r} \frac{\partial c_{\mathrm{d}}}{\partial r}\right)+\frac{\partial}{\partial z}\left(D_{\mathrm{d}} \frac{\partial c_{\mathrm{d}}}{\partial z}\right)\right\}$

Initial conditions $t=0, c_{\mathrm{d}}=c_{\mathrm{d} 0} \quad$ inside of tablet Boundary condition $t>0, c_{\mathrm{d}}=0$ on all surface of tablet

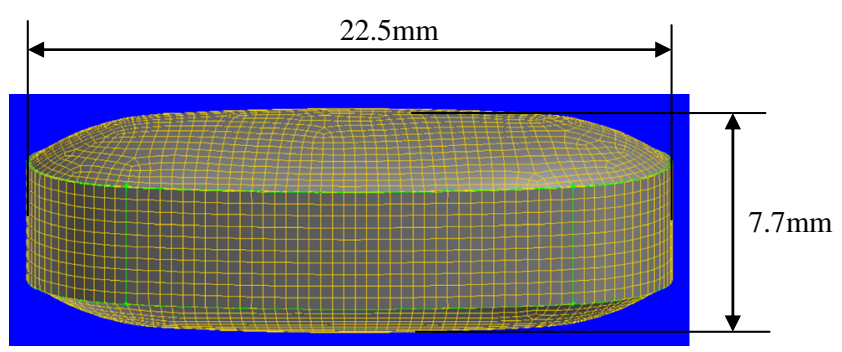

Fig. 1. Tablet tooling geometry and computational domain
The dissolution profile for the Met XR 1000 mg tablet was investigated by the model. The tablet geometry information is listed in Fig. 1 and Table I. CFD was applied to solve Eq. 1 to obtain the simulated dissolution profile for a tablet compressed using tooling $\mathrm{E}$ was shown as the solid line in Fig. 2 using the fitted model parameter, the diffusivity of the drug $D_{\mathrm{d}}=1.15 \times 10^{-10} \mathrm{~m}^{2} / \mathrm{s}$, by the experimental data. As shown in Fig. 2, the simulated dissolution profile and actual dissolution of three separate lots of tablets compressed using tooling $\mathrm{E}$ were very similar for up to the first $400 \mathrm{~min}$ in the dissolution run. At the later time point, there was some divergence between the simulated and actual dissolution profiles probably because of an erosion of the HPMC-based tablet matrix (Fig. 2). The model has $R^{2}$ of 0.99 ; overall, the relative standard deviation between the experimental and predicted drug dissolved is $11.5 \%$ and these data further validated the model.

Compared to the CFD approach above which can be used in more detail to evaluate the effect of the tablet size and

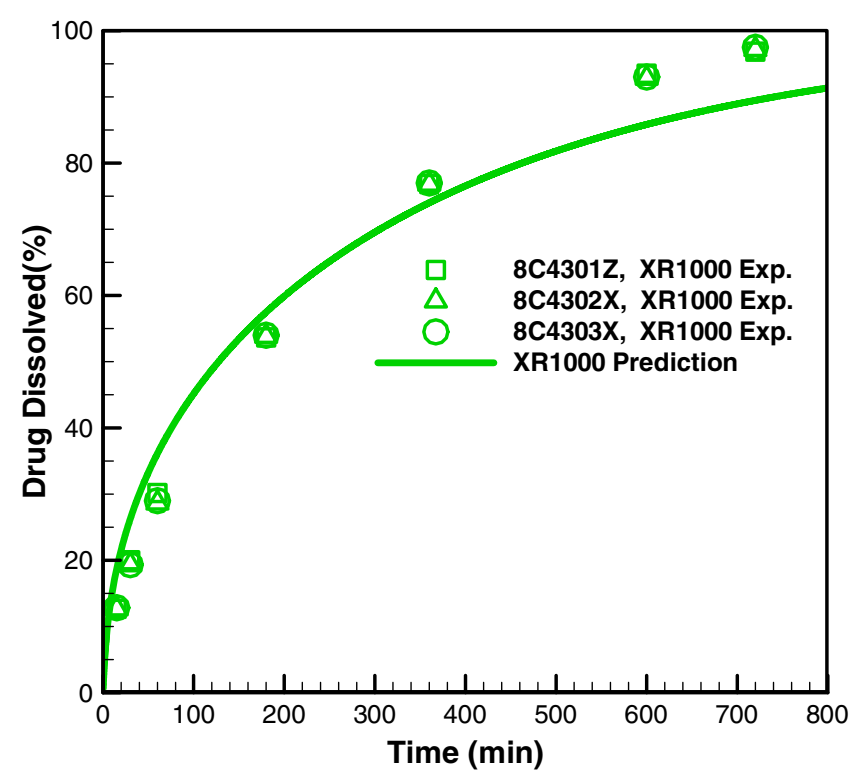

Fig. 2. Simulated versus actual dissolution profiles of Met XR $1000 \mathrm{mg}$ tablets compressed using E tooling 
shape on the drug dissolution profile, Eq. 2 is an approximate solution (12) to Eq. 1. This was proposed by Lapidus and Lordi to describe a drug release from swellable HPMC tablet matrices (2). The relation between the dissolution profile and $\mathrm{SA}$ /volume ratio and diffusivity can also be seen from this equation.

$\frac{M_{\mathrm{t}}}{M_{0}}=2\left(\frac{\mathrm{SA}}{\mathrm{Vol}}\right)\left(\frac{D_{\mathrm{eff}} t}{\pi}\right)^{\frac{1}{2}}$

where $M_{\mathrm{t}}$ is the amount of drug dissolved at time $t, M_{0}$ is the drug in the original dry tablet and SA and Vol are the surface area and volume of the tablet, respectively. $D_{\text {eff }}$ is the effective drug diffusivity in the tablet.

Lapidus and Lordi's model is adopted from Higuchi's model by using volume/surface area to approximate the characteristic diffusion length $(2,13)$. Both Higuchi's model and the CFD method solved the mass transfer equation (drug) based on Fick's law within the tablet, but they have differences in the algorithm and computational domain. Higuchi's model gives an analytical solution for a typical computational domain (tablet) like plate, cylinder, and sphere, which is an infinite series and difficult to use. On the other hand, CFD uses the finite element volume (FEV) (13) approach to give a numerical solution for the arbitrary computational domain which can mimic any shape of the tablets.

Generally, the diffusivity in Fick's law for the control release has been obtained through fitting the experimental data by these models (13). In this work, the diffusivities for Lapidus and Lordi's model and CFD are $8.0 \mathrm{e}-11$ and $1.15 \mathrm{e}-10 \mathrm{~m}^{2} / \mathrm{s}$, respectively. With this diffusivity, Lapidus and Lordi's model has $R^{2}$ of 0.99 and the relative standard deviation between the experimental and predicted drug dissolved is $13.9 \%$. When the diffusivity from CFD is used in the prediction by Lapidus and Loris' model, a different drug release profile can be seen in Fig. 3. This difference was not caused by the model itself but the simplification in deriving Lapidus and Lordi's equation. Lapidus and Lordi (Higuchi (13) make an approximation by keeping the first term and omitting the rest of the series under the condition that the drug percent

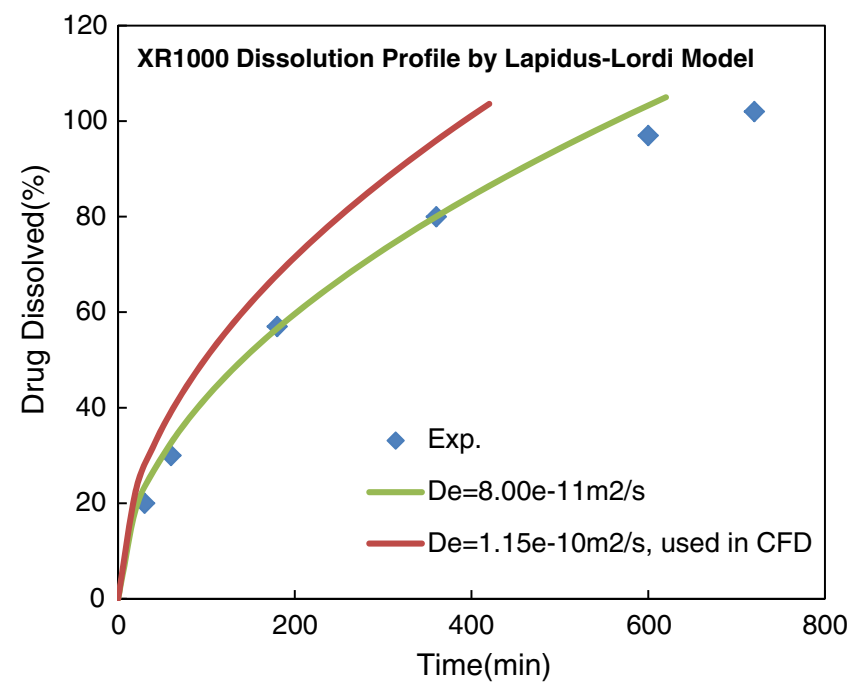

Fig. 3. The drug release profile with different diffusivities predicted by the Lapidus-Lordi model release is less than $30 \%$ (a practical consideration for use). Additionally, the approximation about the characteristic diffusion length (volume/surface area) is used in Lapidus-Lordi's model compared with the typical characteristic diffusion length (plate $\mathrm{L} / 2$, cylinder $\mathrm{R} / 2$, sphere $\mathrm{R} / 3$ ), which is another source of the discrepancy. When the shape of the tablet is close to the typical geometry, the discrepancy is less. However, when the shape is far from the typical geometry, the discrepancy becomes larger. CFD model is also simplified compared to Siepmann's model $(9,10)$ by implicitly using the effective diffusivity that includes the swelling effects. The diffusivity used in the CFD prediction of Met XR 1000 tablet dissolution profile is validated by Met XR750 tablet (reference product) due to the same formulation. Moreover, the CFD model can evaluate the effect of the complex geometry (tooling shape and size) on the dissolution profile by discerning the computational domain and avoid using volume/surface area as the characteristic diffusion length.

It can be demonstrated from Eq. 2 that when surface area (SA)/volume ( Vol) ratio is kept constant, the drug release should be similar for tablets with different shapes. The practical utility of keeping tablet surface area/volume ratio constant to achieve a similar release profile using different tooling shapes or different doses was demonstrated by Reynold et al. (4). Based on this information, during the development of high-strength Met XR tablet, it was decided to keep its SA/Vol ratio similar to Met XR $750 \mathrm{mg}$ which was shown bioequivalent to the reference product Met XR $500 \mathrm{mg}$ (Glucophage ${ }^{\mathrm{TM}}$ XR 500) by comparing two tablets of Met XR 750 to three tablets of Met XR 500. Several tooling designs were evaluated to identify appropriate tooling for tablet compression. The desired surface area was not feasible with size "B" tooling because of the large target tablet weight of $1450 \mathrm{mg}$ for the high-strength Met XR tablet. Six different tooling shapes (size "D") were evaluated for the development of high-strength Met XR tablets. Their descriptions, dimensions, and vendor's names are provided in Table I. The surface area and volume for each tooling shape was calculated using Gambit software (Gambit 2.4.6 software, 2006, Fluent Co., Lebanon, $\mathrm{NH}$ ).

As shown in Table I, the SA/Vol ratio of Met XR $750 \mathrm{mg}$ was 15.94 (1/in.). The various tooling designs had SA/Vol ratio varying from 13.70 to 14.64 (1/in). According to Eq. 2, larger SA/ Vol results in faster dissolution rate. Moreover, with the same volume, larger surface area can increase the mass transfer area results in faster dissolution rate. With similar value of SA/Vol of the different tooling designs in this study, they show the similar dissolution profile seen in the dissolution data of $1000 \mathrm{mg} \mathrm{Met}$

Table II. Mean Dissolution Data of $1000 \mathrm{mg}$ Met XR Compressed to Press Weight of $1450 \mathrm{mg}$ Using Tooling of Different Shapes. The Values are \% Metformin Dissolved

\begin{tabular}{lllll}
\hline $\begin{array}{l}\text { Time } \\
\text { (minutes) }\end{array}$ & $\begin{array}{c}\text { Met XR 750 } \\
\text { as reference }\end{array}$ & Tooling A & Tooling C & Tooling E \\
\hline 30 & 21 & 19 & 20 & 20 \\
60 & 30 & 29 & 29 & 30 \\
180 & 56 & 55 & 54 & 57 \\
360 & 79 & 77 & 77 & 80 \\
600 & 94 & 93 & 93 & 97 \\
720 & 97 & 96 & 98 & 102 \\
\hline
\end{tabular}

$N=6$, standard deviation was around $1 \%$ for all the data. 
Table III. Dissolution Profiles of Metformin XR 1000 mg Tablets Compared to 2×Metformin XR 500 mg Tablets in Three Different Dissolution Media. The Values are \% Metformin Dissolved

\begin{tabular}{|c|c|c|c|c|c|c|}
\hline \multirow[b]{2}{*}{$\begin{array}{l}\text { Time point } \\
\text { (min.) }\end{array}$} & \multicolumn{2}{|c|}{ Potassium phosphate buffer ( $\mathrm{pH}$ 6.8) } & \multicolumn{2}{|c|}{ Sodium acetate buffer ( $\mathrm{pH} 4.5)$} & \multicolumn{2}{|c|}{$0.1 \mathrm{n}$ hydrochloric acid solution ( $\mathrm{pH} 1.2$ ) } \\
\hline & $\begin{array}{l}2 \times 500 \mathrm{mg} \text { Met XR } \\
f 2=75\end{array}$ & $1 \times 1000 \mathrm{mg}$ Met XR & $\begin{array}{l}2 \times 500 \mathrm{mg} \text { Met } \mathrm{XR} \\
f 2=88\end{array}$ & $1 \times 1000 \mathrm{mg}$ Met XR & $\begin{array}{l}2 \times 500 \mathrm{mg} \text { Met } \mathrm{XR}^{1} \\
f 2=90\end{array}$ & $1 \times 1000 \mathrm{mg}$ Met XR \\
\hline 15 & 13 & 12 & 13 & 13 & 14 & 13 \\
\hline 30 & 19 & 19 & 19 & 19 & 20 & 19 \\
\hline 60 & 28 & 28 & 28 & 29 & 29 & 29 \\
\hline 180 & 51 & 53 & 52 & 54 & 54 & 54 \\
\hline 360 & 72 & 75 & 75 & 77 & 78 & 77 \\
\hline 600 & 86 & 92 & 91 & 92 & 92 & 94 \\
\hline 720 & 91 & 96 & 95 & 97 & 96 & 98 \\
\hline
\end{tabular}

$N=12$, standard deviation was around $1 \%$ for all the data.

XR compressed using tooling A, C, or E (Table II). The dissolution data of $1000 \mathrm{mg}$ Met XR compressed using tooling A, C, or $\mathrm{E}$ are shown in Table II. Dissolution data of Met XR 750 was shown as a reference (Table II). In addition to SA/Vol ratio, there were few additional factors taken into consideration in the identification of tooling. It was determined that with a $1450-\mathrm{mg}$ tablet press weight, longer tablets would be difficult to swallow relative to comparatively shorter tablets. Based on this consideration, tooling B, D, and F were dropped since the tablet length would be larger than 0.9 in. Tablets compressed using tooling A showed significant twining (two or more tablets sticking together for their entire length) during the coating operation so this tooling shape was also dropped. Tablets compressed using tooling $\mathrm{C}$ did not have correct orientation to land in the preferred position for the printing operation. It is desirable to have a difference of about 0.100 in. between tablet thickness and width to land the tablet correctly in a tablet printer. For this reason, tooling $\mathrm{C}$ was not further considered. Thus, ease of swallowing, absence of twining during the coating operation, and preferred orientation during the printing operation led to the selection of the oval/modified capsule-shaped tooling (E) for the development of high-strength XR tablets. A summary of the tooling-related elements is also mentioned in Table I comments.

Glucophage ${ }^{\circledR}$ XR 500 and $750 \mathrm{mg}$ are commercial products in the USA. Since $1000 \mathrm{mg}$ Met XR is a higher strength tablet than those already commercially available, a BE study was needed based on the guidance for bioavailability and bioequivalence studies for orally administered drug products (6) and guidance for extended-release oral dosage forms (5). Since Glucophage XR $500 \mathrm{mg}$ was identified as a reference product for a BE study, dissolution of $2 \times$ Glucophage XR 500 tablets was compared against one Met XR $1000 \mathrm{mg}$ in three different media namely $0.1 \mathrm{~N} \mathrm{HCl}(\mathrm{pH} 1.2), 50 \mathrm{mM}$ sodium acetate buffer $\mathrm{pH} 4.5$, and $50 \mathrm{mM}$ potassium phosphate buffer $(\mathrm{pH}$ 6.8). As shown in Table III, dissolution of Met XR 1000 was similar to $2 \times$ Glucophage $500 \mathrm{mg}$ in three different media with $f 2$ values ranging from 75 to 90 . Dissolution profiles with $f 2$ values higher than 50 are considered similar (14).

Metformin pharmacokinetics has been extensively reported by numerous groups $(9,15-17)$. It was shown that the

Table IV. GastroPlus Model Parameters

\begin{tabular}{lll}
\hline & Parameter & Value \\
\hline Physical-chemical & Dose & $1000 \mathrm{mg}$ \\
Physiology & Log D & $-3.37(\mathrm{pH} 4)$ \\
& Fed state & GastroPlus default values $2.2 \times 10^{-4} \mathrm{~cm} / \mathrm{s}$ \\
Absorption scale factors & Permeability (jejunum) & \\
& Duodenum & 0.549 \\
& Jejunum 1 & 0.540 \\
& Jejunum 2 & 0.536 \\
& Ileum 1 & 0.530 \\
& Ileum 2 & 0.500 \\
Ileum 3 & 0.707 \\
Caecum & 0.015 \\
& Ascending colon & 0.015 \\
& Clearance & $0.61[\mathrm{~L} /(\mathrm{h} \mathrm{kg})]$ \\
& Volume of distribution (central) & $0.578 \mathrm{~L} / \mathrm{kg}^{-1}$ \\
& K12 & $1.92 \mathrm{~h}^{-1}$ \\
& K21 & $1.03 \mathrm{~h}^{-1}$ \\
& K13 & $0.137 \mathrm{~h}^{-1}$ \\
\end{tabular}




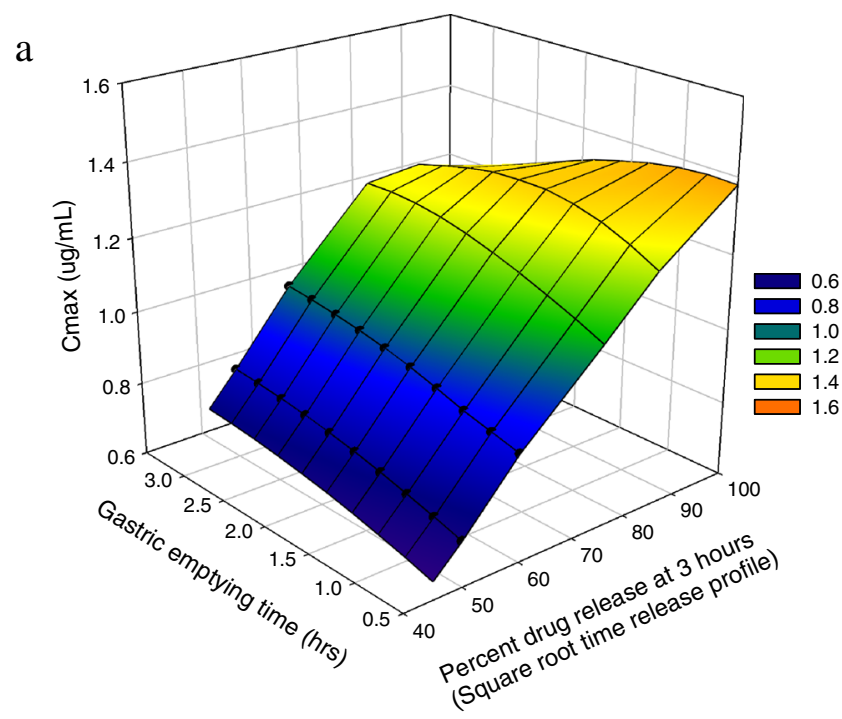

$\mathrm{b}$

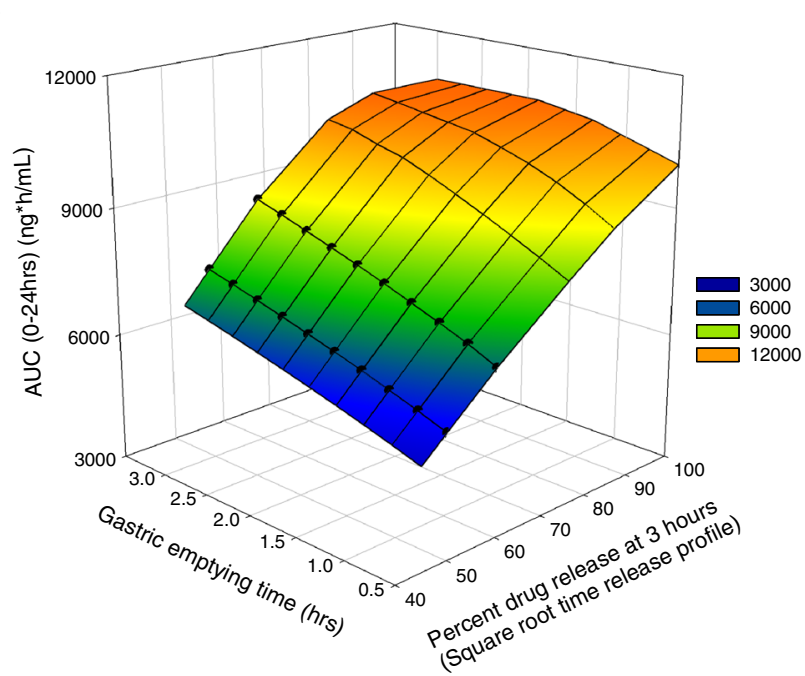

Fig. 4. $C_{\max }$ and AUC (0-24) vs. gastric emptying and drug release (in vivo drug release proportional to the square root of time)

metformin bioavailability decreases as Glucophage XR dose is increased beyond the starting dose of $500 \mathrm{mg} \mathrm{(7).} \mathrm{Therefore,}$ similarity in dissolution of $2 \times$ Glucophage XR 500 and $1000 \mathrm{mg}$ Met XR similarity in dissolution may not lead to positive BE results. In order to mitigate the risk of a $\mathrm{BE}$ failure, a PK absorption model was used to predict exposure in humans for $1000 \mathrm{mg}$ Met XR. Using the physicochemical and pharmacokinetic properties of metformin, a pharmacokinetic absorption model was developed using GastroPlus ${ }^{\mathrm{TM}}$ V.7.0 software (9). Detailed parameters of the model are listed in Table IV. In vitro dissolution kinetics and the available human pharmacokinetic data were used to parameterize the absorption model. Figure 4 shows the simulated effect of drug release and gastric emptying on the pharmacokinetic parameters $C_{\max }$ and $\mathrm{AUC}_{(0-24)}$ for release proportional to the square root of time, which is the approximate behavior typically observed from swellable hydrophilic matrix tablets. In rare cases, a matrix could exhibit a constant surface area during in vivo release (no swelling) that would result in a zero order release and this occurrence can similarly be modeled to predict exposure. Plots in Fig. 4 include symbols (black circles) for the closest release profiles $(50-60 \%$ dissolved at $3 \mathrm{~h})$ that bracket the observed behavior for metformin XR tablets (Table III). These exposures agree closely with the observed clinical behavior and if anything very slightly under predict because square root of time release kinetics do well to represent diffusion-dominant in vitro dissolution for hydrophilic matrix tablets, but often do not describe some additional release from erosion anticipated to occur in vivo. Additionally, the Fig. 4simulated AUC period was $24 \mathrm{~h}$ less than the $48 \mathrm{~h}$ PK monitoring period in the clinical bioequivalence study. The utility of these types of surface plots enables the formulator to easily select an in vitro release profile that will provide the necessary therapeutic $C_{\max }$ and AUC.

The GastroPlus absorption model projected in vivo profile of the high-strength XR tablet to be equivalent to $2 \times 500 \mathrm{mg}$ Glucophage XR. Ultimate clinical BE studies comparing $1000 \mathrm{mg}$ Met XR to $2 \times 500 \mathrm{mg}$ Met XR showed that the new tablet met the AUC criteria for $\mathrm{BE}$ indicating similar exposure. However, the $C_{\max }$ was increased by $17 \%$, and the $90 \%$ confidence interval ratio of $C_{\max }$ geometric means extended above the $\mathrm{BE}$ range of 80 to $125 \%$ for the first $\mathrm{BE}$ study (Table V). Thus, the BE criteria for $C_{\max }$ was not achieved (Table V). However, in the second BE study, both $C_{\max }$ and AUC criteria were achieved (Table V). For a once daily metformin dosage form, overall exposure is more important from a treatment perspective given the wide clinical dose range of 500 to $2550 \mathrm{mg}$. Since Met XR $1000 \mathrm{mg}$ met the AUC criteria in the both BE studies, it was selected for further development.

Table V. Results of Statistical Analysis of Metformin Cmax, AUC (inf.), and AUC (0-48 h)

\begin{tabular}{|c|c|c|c|c|}
\hline \multirow[t]{2}{*}{ Pharmacokinetic parameter (fed state) } & \multicolumn{2}{|c|}{ Adjusted geometric means } & \multicolumn{2}{|c|}{ BA ratio adjusted geometric means } \\
\hline & $\begin{array}{l}\text { Glucophage XR } \\
2 \times 500 \mathrm{mg}\end{array}$ & $\begin{array}{l}\text { Met XR } \\
1 \times 1000 \mathrm{mg}\end{array}$ & Point estimate & $90 \%$ C.I. \\
\hline \multicolumn{5}{|l|}{ Study $1(n=13)$} \\
\hline AUC (INF) (ng/ml.h) & 9560 & 9701 & 1.015 & $(0.965,1.067)$ \\
\hline AUC (0-48 h) (ng/ml.h) & 9419 & 9568 & 1.016 & $(0.966,1.068)$ \\
\hline$C_{\max }(\mathrm{ng} / \mathrm{mL})$ & 735 & 861 & 1.171 & $(1.037,1.323)$ \\
\hline \multicolumn{5}{|l|}{ Study $2(n=30)$} \\
\hline AUC (INF) (ng/ml.h) & 9746.3 & 8713.4 & 0.894 & $(0.833,0.959)$ \\
\hline AUC (0-48 h) (ng/ml.h) & 9246.8 & 8377.8 & 0.906 & $(0.848,0.968)$ \\
\hline$C_{\max }(\mathrm{ng} / \mathrm{mL})$ & 1151.2 & 1055.9 & 0.917 & $(0.859,0.980)$ \\
\hline
\end{tabular}




\section{CONCLUSIONS}

Three separate mathematical models were utilized for the accelerated development of Met XR $1000 \mathrm{mg}$ tablets using the existing granulation of Met XR $750 \mathrm{mg}$. This approach kept the surface area/volume ratio of the new high-strength tablet similar to the commercial product Met XR 750 (Glucophage XR 750). Met XR 750 was bioequivalent to Glucophage XR 500 by comparing two tablets of Met XR 750 with three tablets of Met XR 500. Although the tablet weight of Met XR $1000 \mathrm{mg}$ was increased by about $400 \mathrm{mg}$, the dissolution profile was similar to Met XR 750 and close to the predicted dissolution using Fluent software. Finally, the absorption model created using the GastroPlus software projected in vivo exposure (AUC) of $1000 \mathrm{mg}$ Met XR equivalent to $2 \times 500 \mathrm{mg}$ Glucophage $\mathrm{XR}$ which was verified by actual $\mathrm{BE}$ studies. Thus, all three models not only accelerated the development of Met XR $1000 \mathrm{mg}$ but increased the likelihood of success.

\section{REFERENCES}

1. Siepmann J, Peppas NA. Modeling drug release from delivery systems based on hydroxypropyl methylcellulose (HPMC). Adv Drug Deliv Rev. 2001;48:139-57.

2. Lapidus H, Lordi NG. Drug release from compressed hydrophilic matrices. J Pharm Sci. 1968;57(8):1292-301.

3. Jensen K. Microreaction engineering-is small better? Chem Eng Sci. 2001;56:293-303.

4. Reynolds TD, Mitchell SA, Balwinski KM. Investigation of the effect of tablet surface area/volume on drug release from hydroxypropylmethylcellulose controlled-release matrix tablets. Drug Dev Ind Pharm. 2002;28(4):457-66.

5. GuidanceforIndustry. SUPAC-MR: modified release solid oral dosage forms, scale-up and postapproval changes: chemistry,manufacturing, and controls; in vitro dissolution testing and in vivo bioequivalence documentation. Center for Drug Evaluation and Research (CDER). 1997.

6. Guidanceforindustry. Bioavilability and bioequivalence studies for orally administered drug products-general considerations. Center for Drug Evaluation and Research (CDER). 2000.

7. Timmins P, Donahue S, Meeker J, Marathe P. Steady-state pharmacokinetics of a novel extended-release metformin formulation. Clin Pharmacokinet. 2005;44(7):721-9.

8. Timmins P, Dennis AB, Vyas KA. InventorsBiphasic controlled release delivery system for high solubility pharmaceuticals and method. USA. 2002.

9. Crison JR, Timmins P, Keung A, Upreti VV, Boulton DW, Scheer BJ. Biowaiver approach for biopharmaceutics classification system class 3 compound metformin hydrochloride using in silico modeling. J Pharm Sci. 2012;101(5):1773-82.

10. Siepmann F, Eckart K, Maschke A, Kotler K, Siepmann J. Modeling drug release from PVAc/PVP matrix tablets. J Control Release. 2010;141:216-22.

11. Siepmann J, Poduk K, Sriwongjaya N, Peppas N, Bodmeier R. A new model describing the swelling and drug release kinetics from hydroxypropylmethyl cellulose tablets. J Pharm Sci. 1999;88:65-72.

12. Desai D, Kothari S, Chen W, Wang J, Huang M, Sharma L. Fatty acid and water-soluble polymer based controlled drug delivery system. J Pharm Sci. 2011;100:1900-12.

13. Higuchi WI. Analysis of data on the medicament release from ointments. J Pharm Sci. 1962;50(8):802-4.

14. Moore JW, Flanner HH. Mathematical comparison of dissolution profiles. Pharm Technol. 1999;20(6):64-74.

15. Balan $\mathrm{G}$, Timmins $\mathrm{P}$, Greene DS, Marathe $\mathrm{PH}$. In vitro-in vivo correlation (IVIVC) models for metformin after administration of modified-release (MR) oral dosage forms to healthy human volunteers. J Pharm Sci. 2001;90(8):1176-85.

16. Duong JK, Kumar SS, Kirkpatrick CM, Greenup LC, Arora M, Lee TC, et al. Population pharmacokinetics of metformin in healthy subjects and patients with type 2 diabetes mellitus: simulation of doses according to renal function. Clin Pharmacokinet. 2013;52(5):373-84.

17. Graham GG, Punt J, Arora M, Day RO, Doogue MP, Duong JK, et al. Clinical pharmacokinetics of metformin. Clin Pharmacokinet. 2011;50(2):81-98. 